\title{
La encíclica apócrifa de León XIII: un episodio del anticlericalismo latinoamericano*
}

The Apocryphal Encyclical of Leo XIII: An Episode of Anticlericalism Latin

\section{Gerardo Alberto Hernández Aponte}

A mi colega Amira del Valle Juri

En el (sic) Vaticano se ha recibido noticia de una Encíclica publicada

por los periódicos de Sur América, en cuyo documento se autoriza á los sacerdotes residentes en la citada parte del mundo á contraer matrimonio, en virtud de las consideraciones y motivos que aquel expresa. ${ }^{1}$

\section{Resumen}

Este artículo es un análisis de un suceso al parecer hasta ahora ignorado por la historiografía eclesiástica referido a la publicación en 1899 de una encíclica apócrifa del papa León XIII en diversos periódicos latinoamericanos. Este escrito es ante todo, una propuesta para estudiar las repercusiones que tuvo el documento en diversos países a fin de tener una visión global del asunto.

Palabras claves: Concilio, liberalismo, celibato, masonería, anticlericalismo.

\section{Abstract}

This paper describes and analyzes an event apparently hitherto ignored by ecclesiastical historiography. I am referring to the publication of an apocryphal encyclical of Pope Leo XIII by several latinamerican newspapers in 1899. This paper is primarily a proposal to study the repercussions the pseudo document had in different countries in order to then be able to have a total view of the matter.

Keywords: Plenary Council of Latin America, liberalism, celibacy, freemasonry, anticlericalism, Pope Leo XIII.

- Fecha de recepción del artículo: 09-01-2013 • Fecha de aceptación: 30-01-2013

GERARDO ALBERTO HERNÁNDEZ APONTE. Especialista en Historia de la Universidad de Puerto Rico, Recinto de Río Piedras. Doctor en Filosofía. Profesor en la Universidad Interamericana de Puerto Rico, Recinto Metropolitano. Miembro de la Asociación Latinoamericana para el Estudio de las Religiones (ALER).

* Artículo de reflexión no derivado de investigación.

1. El Ideal Católico, Puerto Rico, 6 de enero de 1900, p. 174. 


\section{Introducción}

En 1899 algunos rotativos puertorriqueńos anunciaban la noticia de que varios periódicos latinoamericanos habían publicado una alegada encíclica ${ }^{2}$ del papa León XIII redactada a raíz del Concilio Plenario de la América Latina celebrado en Roma ese mismo año, en la cual se afirmaba que el papa León XIII había abolido el celibato eclesiástico para los sacerdotes seculares de América Latina. La noticia, publicada en un momento en el que algunos sectores de la sociedad latinoamericana buscaban conciliar el catolicismo con la modernidad, provocó diversas reacciones tanto en el seno de la iglesia como en la sociedad; sin embargo, tiempo después la prensa informó que el documento era apócrifo. En este artículo analizo el escrito en cuestión, la reacción de la prensa y del clero de Puerto Rico y el contexto histórico en el que fue publicado ${ }^{3}$. Finalmente, invito a otros investigadores a que se interesen en el tema y traigan luz en cuanto a las repercusiones que tuvo en los países latinoamericanos.

\section{Antecedentes del Concilio Plenario de la América Latina}

Joaquín Pecci fue elegido papa el 20 de febrero de 1878 y se impuso el nombre de León XIII. Desde su nombramiento como arzobispo de Perusa en 1846 se había distinguido por avivar la presencia operante de la Iglesia en la sociedad mediante iniciativas doctrinales y pastorales y valorar los elementos de la modernidad que consideraba compatibles con la doctrina de la Iglesia. Por ejemplo, el liberalismo ${ }^{4}$ y la doctrina cristiana católica romana coincidían en juzgar la libertad del ser humano como componente esencial de su dignidad, una fusión perfecta de los valores cristianos con el mundo moderno. No obstante lo anterior, el papa debió hacer claridad acerca de las diferencias entre dicho concepto y los planteamientos en ese mismo sentido de los pensadores liberales (López, 1997, pp. 19-20, 23). Su pontificado de veinticinco años (1878-1903) se destacó -entre otros aspectos- por la internacionalización de la Santa Sede mediante sus representantes diplomáticos. En cuanto a su política en relación con los pueblos latinoamericanos, el sumo pontífice se esforzó decididamente por su unificación y en este sentido el Concilio Plenario de la América Latina celebrado bajo su pontificado, dio inicio a una decidida articulación de las diferentes Iglesias latinoamericanas y orientó todo su esfuerzo a constituir a Latinoamérica como una unidad católica. De este modo, configuró una gran familia de tradición católica romana sin distinciones geográficas, étnicas o lingüísticas (Pazos, 2000, pp. 153-155) y logró que un episcopado hasta ese momento ignorante de los lazos que compartían comenzara a vivir con particular intensidad la unidad eclesiástica instaurada por León XIII. Este fue sin duda uno de sus principales logros y como fruto de esa experiencia conciliar nacieron las conferencias episcopales de cada país y el Consejo Episcopal Latinoamericano (Celam) (González, 2000, pp. 315) cuyos decretos estuvieron vigentes en Latinoamérica hasta el comienzo del Concilio Vaticano II en 1962 (Alejos Grau, 2005, pp. 302).

\section{Celebración del Concilio Plenario de la América Latina}

El Concilio Plenario de la América Latina celebrado en Roma del 28 de mayo al 9 de julio de $1899^{5}$, buscaba establecer la unidad legislativa en las antiguas posesiones de España y Portugal sobre la base de compartir una lengua, una cultura y una experiencia histórica así como instituciones coloniales gubernamentales y eclesiásticas y un mismo proceso formativo por haber sido colonizadas por estos dos países. Particularmente, el concilio bus-

2. Una encíclica es un documento pontificio dirigido a toda la Iglesia católica romana, a varias iglesias particulares o a los prelados de una determinada nación que trata sobre asuntos de la Iglesia o de la doctrina católica romana. Suele estar redactado en latín y su título se toma de las primeras palabras del documento. Existen otros documentos de naturaleza pontificia tales como breves, bulas, alocuciones, quirógrafos, motu proprio y oracula vivae vocis, entre otros. Explicar cada uno de ellos está fuera de los alcances de este escrito. (Encíclicas, 1959, pp.19-20).

3. Mientras investigaba en la prensa insular para mi disertación doctoral me topé con varias gacetillas relativas a la pseudo encíclica de León XIII. Este artículo es fruto de su análisis. .

4. Defino al liberalismo como una ideología político-filosófica que se oponía a la autoridad absoluta del Estado, la Iglesia católica o cualquier institución. En otras palabras, estaba en contra de todo tipo de restricción que limitara irrazonablemente el ejercicio de la libertad natural (Laski, 1939, pp. 6-10).

5. Para sus decretos véase: Actas, 1999. 
caba solucionar aquellos problemas que la Iglesia de América Latina venía enfrentando desde la época colonial los cuales se reducían básicamente a cinco: diócesis y parroquias muy extensas que dificultaban la labor pastoral, pues cada sacerdote tenía a su cargo un número considerable de fieles; el alto número de concubinatos por falta de párrocos y dinero para pagar el estipendio establecido para el trámite matrimonial amén de la dificultad que significaba la lejanía de los templos; la escasez ministerial, el comportamiento impropio y la ignorancia de un sector del clero; el surgimiento de gobiernos liberales anticlericales; y por último, el surgimiento y desarrollo de un liberalismo de corte anticlerical, y la aparición de la masonería y otros movimientos seculares. Puesto que eran problemas habituales de todas las diócesis latinoamericanas y dada su idiosincrasia común, se determinó legislar en conjunto para todas ellas.

Ante este panorama Roma propuso la celebración del citado concilio el cual no estaría dirigido a la aprobación de normas nuevas, sino a fusionar el magisterio de los papas León XIII y Pío IX y a compilar documentos eclesiales considerados capitales y velar por su cumplimiento. Se promulgaron además algunas normas dada la particularidad e idiosincrasia de Latinoamérica, se dio carácter de ley a todas sus disposiciones para los territorios y se enfocó en formar mejor al clero, unificar la legislación eclesial para América Latina, especificar qué tipo de relación debía haber entre la Iglesia y el Estado e involucrar más a los laicos en los trabajos eclesiales (Pazos y Piccardo, 2002, pp. 12-13, 18, 21-61, 97, 143-147; Saranyana, 2005, pp.19-27).

Por otro lado, el concilio hacía parte de una política más amplia iniciada por Pío IX (1846-1878) y continuada por León XIII encauzada a reformar la Iglesia. Este proyecto ha sido calificado por la historiografía eclesiástica como la romanización y consistía en centralizar el poder a fin de fortalecer la autoridad de la jerarquía romana. Al finalizar el dominio español finiquitó con él la institución del Patronato Real y ante este escenario la santa sede dirigió su agenda a la recuperación de los espacios políticos y sociales (sin contar con el apoyo de los gobiernos) y a contrarrestar la secularización que poco a poco se apoderaba de la mayoría de esos países y fue precisamente la realización del concilio ${ }^{6}$ una de las estrategias para lograr este propósito (Bautista García, 2005, pp. 100, 104-106, 138-139). Se uniformó, entonces, la legislación eclesial para Latinoamérica y se afianzó el poder del pontificado, así la Iglesia de América Latina centró en el papa su modus operandi (Bautista García, 2005, pp. 101; Sanz, 2000, pp. 1274, 1281; Pazos, 1998, pp.187-188). Además, el concilio hizo que la santa sede se diera cuenta de que era necesaria una legislación canónica para toda la Iglesia y de esta forma se constituyó en un precursor del proceso de elaboración del Código de Derecho Canónico de 1917 (Sanz, 2000, pp. 1281-1284; Aguer, 2000, pp. 242-243; Alejos Grau, 2000, pp. 419-427; Cuenca Toribio, 1972, pp. 562; Martínez de Artola, 2003, pp. 411).

\section{El pseudo documento pontificio}

La historiografía sobre el Concilio Plenario de la América Latina se ha concentrado mayormente en estudiar las causas que propiciaron su celebración así como su aplicación en los países latinoamericanos $^{7}$ (Pazos y Piccardo, 2002; los últimos, 2000); sin embargo, hay asuntos que permanecen aún en espera de ser investigados. Uno de ellos es la encíclica apócrifa publicada por algunos rotativos de América Latina entre ellos El Heraldo de Costa Rica ${ }^{8}$. El documento pontificio fue promulgado supuestamente el 10 de julio de 1899, es decir, un día después de haber finalizado el concilio; como corolario, se afirmaba que era producto de la citada reunión.

6. Hubo otras estrategias pero explicarlas todas está por fuera de los límites de este artículo.

7. Hasta ahora el primer estudio global sobre el concilio se remonta a una tesis doctoral de Felipe Cejudo Vega de la Universidad de Ottawa en 1948. En 1973 hubo otra disertación realizada por María M. Esandi en la Université de Louvain que versó sobre los padres conciliares. En 1980 Flavia Morando hizo otro estudio general para su tesis en la Università di Roma. Sin embargo, no será hasta finales de la década de 1990 que tomen auge los estudios sobre el tema debido a que se cumplía el centenario. Como parte de la celebración de ese acontecimiento se celebró en Roma un simposio histórico cuyas actas están publicadas (Pazos y Piccardo, 2002, pp. 15-17)

8. La Correspondencia de Puerto Rico, 7 de diciembre de 1899, p. 3; La Democracia, (Puerto Rico) 9 de febrero de 1900, p. 3. La prensa espańola publicó que algunos diarios alemanes y franceses que simpatizaban con el protestantismo reprodujeron la noticia. Sin embargo, uno de ellos la Kölnische Volkszeitung (Gaceta del Pueblo de Colonia) expuso que el documento era falso. Véase: El Imparcial, (Madrid), 31 de diciembre de 1899, p. 2. 
El texto declaraba que el papa León XIII había abolido el celibato sacerdotal para los presbíteros seculares de Latinoamérica - decisión que se haría efectiva a partir del primero de enero de 1900 basada en que el celibato no era de carácter divino sino estipulado por los pontífices y los concilios que buscaban una mayor pureza en la celebración de los sacramentos junto con el celo y la abnegación exigida a los presbíteros. La imposición del celibato -aducía- ocurrió en un momento en el que existían muchas vocaciones al ministerio sacerdotal. El segundo punto esgrimido se basaba en que en América Latina, por el contrario, las vocaciones eran escasas por lo tanto muchas poblaciones carecían de sacerdote. El tercer y último argumento giraba en torno al celibato mismo, pues de acuerdo con el documento aquel exigía gracia, virtud y sacrificio, elementos que no eran concedidos por Dios a todos. Además, expuso que si bien era cierto que el celibato brindaba respeto y autoridad al sacerdocio, era un obstáculo para el aumento de vocaciones sacerdotales?

Por las razones antes expuestas, el papa León XIII supuestamente declaró:

[...] dejamos en libertad á los sacerdotes seculares de dicha región, y sólo en razón de las necesidades apremiantes del clero en esas naciones y pueblos, para que puedan abrazar el estado del matrimonio, sujetándose en todo, con respecto á esta materia, á la disciplina general establecida por la Iglesia con respecto á los fieles ${ }^{10}$.

La Democracia fue uno de los primeros periódicos puertorriqueños en dar a conocer la "noticia" en la isla ${ }^{11}$ con la aclaración de que la dispensa era solamente para los curas de América del Sur ${ }^{12}$. Dos días después de su publicación, el semanario rectificó diciendo que se aplicaba para América Latina completa, por lo que Puerto Rico, República Dominicana y Cuba estaban incluidos en el documento pontificio ${ }^{13}$.

En la noticia también se expuso: "No se sulfuren los P. P. Paules (sic) con los periódicos que dan al público la importante nueva. Sulfúrense con el Papa; y, si pueden, levanten un cisma [...]"14.
Con ello se pretendía molestar a los padres paúles quienes a la sazón regentaban la parroquia de Ponce. La Democracia como portavoz del Partido Autonomista, criticó duramente a la Iglesia Católica romana por considerarla decadente, fanática, ambiciosa de poder y opuesta a la razón y a los adelantos científicos y tecnológicos. Frente a esa alegada visión católica esgrimió una visión de Jesucristo como un demócrata vinculado al ideario de libertad, igualdad y fraternidad (Pedreira, 1982, PP. 428; Negrón-Portillo, 1981, pp. 15, 21-22, 28-30). Por este motivo, no fue extraño que hiciera referencia a la congregación religiosa citada y que incitara a sus miembros a separarse de ella. Este llamamiento se dio en un momento francamente desfavorable para los padres paúles puesto que dicha congregación había sido denunciada por el periódico El Buscapié del 25 de agosto de 1898 con base en un artículo del diario estadounidense Herald del 5 de agosto en el que se alegaba que los padres paúles de Ponce se habían hecho ciudadanos estadounidenses y puestos bajo la obediencia del cardenal James Gibbons, de lo cual se infería que desconocerían la autoridad local del vicario capitular Juan Perpiñá y Pibernat (Vicario, 1909, pp. 604-605; Boletin Eclesiástico de la Diócesis de Puerto Rico, 26 de agosto de 1898, pp. 147-148; 3 de septiembre de 1898, pp. 151-152).

Por otro lado, Ponce era la meca del libre pensamiento por lo que el catolicismo contaba con una oposición recalcitrante (Vicario, 1909, pp. 594-596; La Verdad, 24 de agosto de 1912, p. 625). Además, la publicación del texto se dio en un contexto en el que el gobierno estadounidense conquistó la soberanía de la isla para sus propósitos estratégicos militares y económicos al tiempo que enfiló sus baterías hacia la iglesia católica romana ya que, según ellos, representaba un pasado oscurantista y retrógrado. A esta causa se unieron protestantes, masones, espiritistas y librepensadores (Hernández Aponte, 2013, pp. 105-141, 212, 366-367).

Días después de haberse publicado la noticia del pseudo documento pontificio, $\mathrm{La}$ Correspondencia de Puerto Rico reveló que más de veinte sacerdotes

9. La Democracia, (Puerto Rico), 19 de diciembre de 1899, p. 2.

10. Ibid. La cita conserva la ortografía de la época.

11. La Democracia llamó al documento "Breve". Véase : La Democracia, (Puerto Rico), 18 de diciembre de 1899 , p. 2.

12. La Democracia, (Puerto Rico), 16 de diciembre de 1899 , p. 3.

13. Ibid., 18 de diciembre de 1899 , p. 2.

14. Ibid. 
contraerían matrimonio a partir del primero de enero $^{15}$. Como la noticia fue insertada en la sección de noticias que hacían referencia a Puerto Rico, ello hace pensar que el suceso ocurriría realmente, aunque no hay evidencia del hecho. Evidentemente, el documento apócrifo fue creado no solo para generar incertidumbre entre el clero, sino también para incitar a sus miembros a buscar pareja y contraer nupcias. El citado documento auguraba un periodo de poco más de cinco meses para que la dispensa papal se hiciese oficial y su redacción denotaba un conocimiento suficiente del lenguaje de la diplomática eclesial como para dotar de credibilidad a la pseudo encíclica, lo cual sugiere que haya sido redactado por un exsacerdote.

El documento hay que entenderlo en su contexto histórico. A partir de 1850 , se dio un surgimiento sin precedentes del anticlericalismo en los gobiernos liberales latinoamericanos, herederos de la Ilustración y de las ideas de la Revolución Francesa. El carácter de este anticlericalismo era más de índole jurídica y política que religiosa y con base en él se pretendía privar a la iglesia de sus privilegios y su ingerencia en la vida social, económica y educativa y circunscribirla a la práctica religiosa propiamente dicha (Pazos y Piccardo, 2002, pp. 38, 42; Véliz, 1984, pp. 188-189; Fazio, 2000, pp. 643-646; Morales Padrón, 2000, p. 1023; Mallimaci, 2004, pp. 23-24). Esto condujo en ocasiones a violentas luchas dirigidas por los liberales de corte anticlerical, quienes en nombre del progreso y la razón se iban lanza en ristre contra los católicos que reclamaban su fe y sus virtudes cristianas (Véliz, 1984, p. 190).

Los liberales comenzaron, entonces, a construir una modernidad netamente secular y percibieron a la Iglesia católica romana como aliada de los regímenes conservadores ${ }^{16}$ por lo cual la combatieron tenazmente y se consagraron a separarla del Estado y a despojarla de toda prerrogativa política. Algunos católicos liberales intentaron caminos de conciliación mediante la adopción de un catolicismo más progresista a fin de conciliarlo con la modernidad pero sus intentos fracasaron estruendosamente y la Iglesia se vio compelida a unirse a regímenes políticos autocráticos y conservadores. Este estado de cosas incentivó a los liberales para impulsar una modernidad secularizante contraria al catolicismo romano y en este contexto el protestantismo, la masonería y el espiritismo fungieron como difusores del ideario liberal dada la confluencia ideológica de la modernidad democrática y republicana y la economía capitalista (Bastian, 1994, pp. 89-91, 93-94, 103). Durante la década de 1850 la masonería cobró un auge renovador que sirvió de base política al liberalismo y como foco de ataque al catolicismo romano. Por su parte, el protestantismo tenía pocos adeptos y solo será a partir de la Primera Guerra Mundial cuando Latinoamérica empieza a ser considerada tierra de misión (Bastian, 1994, p. 94; Pazos y Piccardo, 2002, pp. 42, 45). Todo este proceso de modernización y progreso de base liberal, encontró apoyo en las corrientes positivistas que comenzaron a ganar terreno a partir de 1870 (Pazos, 2000, p. 46; Ardao, 1950, pp. 67-68) y sustituyeron en algunas mentes la religión revelada por el conocimiento científico. Esta filosofía proveyó la estructura social necesaria para generar los cambios que llevaran a la modernización de los países mediante la adopción de una organización política dirigida por un dictador vitalicio apoyado por un consenso popular y asistido por la élite. Por otro lado, los positivistas acusaron a la iglesia católica romana de dar como un hecho el fracaso político y económico de Latinoamerica (Lynch, 1991, pp. 91-92), lo que sirvió como pretexto a los gobiernos liberales para promover la disidencia religiosa y la afiliación a otras doctrinas (por ejemplo, el protestantismo), con el fin de debilitar a su oponente (Bastian, 1994, pp. 95, 102-103).

En este contexto ideológico se dio la publicación del supuesto documento que eliminaba el celibato sacerdotal, cuyas consecuencias en los diversos países latinoamericanos es necesario estudiar. Por ejemplo, la prensa puertorriqueña informó que en Brasil unos treinta sacerdotes habían contraído nupcias basándose en el citado documento pontificio ${ }^{17}$ cuya veracidad negaron los padres paúles. ${ }^{18}$ Esta congregación religiosa también publicó en el periódico ponceño El Ideal

15. La Correspondencia de Puerto Rico, 18 de diciembre de 1899, p. 2.

16. Fue el comienzo del secularismo radical de hoy día.

17. La Democracia, (Puerto Rico), 9 de febrero de 1900, p. 3.

18. Ibid., 19 de diciembre de 1899 , p. 2. 
Católico un artículo titulado "No hay tal decreto Pontificio" en el que expuso que monseñor James Hubert Blenk obispo de San Juan de Puerto Rico, monseñor Francisco de Paula Barnada y Aguilar arzobispo de Santiago de Cuba, y un sacerdote suramericano llegado a Puerto Rico, habían apoyado el repudio de la comunidad hacia el documento y manifestó asimismo que varios obispos de Suramérica habían desmentido la noticia ${ }^{19}$. Finalmente, en enero de 1900 la prensa puertorriqueña informó que el santo padre había negado su autenticidad e imputado su redacción a una logia masónica establecida en Chile ${ }^{20}$.

Esto hay que entenderlo en un entorno histórico en el que el clero chileno era considerado ejemplar. Esta realidad contrastaba con otras regiones de Latinoamérica como Pará (Brasil) y Huanuco (Perú) donde los sacerdotes vivían en concubinato (Pazos y Piccardo, 2002, p. 31). En este sentido cabe preguntarse: ¿fue redactado el documento apócrifo para perjudicar al clero de Chile solamente? ¿O al de toda Latinoamérica? Durante el siglo XIX llovieron peticiones de diversos sectores para que la iglesia católica romana aboliera el celibato eclesiástico. Por ejemplo, en Brasil entre 1820 y 1840 hubo una serie de debates tanto en la Asamblea Nacional como en la Iglesia Católica con miras a regenerar la Iglesia católica romana en dicha nación. El clero se dividió en dos bandos: unos eran partidarios del celibato y otros estaban a favor de su abolición. Esta última facción estuvo dirigida por el presbítero Diogo Antônio Feijó quien publicó en 1829 un libro titulado Demonstração da Necessidade da Abolição do Celibato Clerical pela Assembléia Geral do Brasile da sua verdadeira e legítima competência nesta matéria.

Por este motivo no es extraño que en 1832 el papa Gregorio XVI expusiera en su encíclica Mirari Vos (Meyer, 2009, pp. 3-4) lo siguiente:

[...] queremos que quede viva vuestra constancia por defender la religión contra una torpísima conjuración (sic) que tiene por blanco el celibato clerical, la cual, como sabéis, se propaga cada día más, y en que colaboran con los extraviados filósofos de nuestros tiempos, también algunos miembros del mismo orden eclesiástico, los cuales... llegaron a tal licencia que en algunos lugares se atrevieron a elevar públicas y reiteradas súplicas a los príncipes para poder infringir aquella santísima disciplina. (Encíclicas, 1959, p. 40)

Pese al reclamo del sumo pontífice el problema persistía. Más de diez años después en 1846, el papa Pío IX insistirá nuevamente en el asunto en su encíclica Qui Pluribus (Encíclicas, 1959, p. 90; Meyer, 2009, p.5) y en 1866 varios sacerdotes húngaros pidieron a la Dieta de Budapest permiso para casarse. Al año siguiente, cuando el papa Pío IX anunció la celebración del Concilio Vaticano I, se despertó en ellos el anhelo de que se pudiera poner en práctica la regla del Concilio griego in Trullo del año 692 como vía de acercamiento a las Iglesias orientales; ${ }^{21}$ sin embargo, el concilio no abordó la cuestión (Meyer, 2009, p. 6; Rodríguez Estrada, 1969, p. 163). ${ }^{22}$ Lo importante es destacar aquí la posibilidad de que el documento fuera redactado para crear un cisma en el clero latinoamericano alrededor del celibato sacerdotal.

También cabe la posibilidad de que hubiese sido publicado con la intención de incentivar la literatura anticlerical. Por ejemplo, a partir de 1863 proliferaron en Francia novelas que retrataban a los presbíteros como propensos a la lujuria, a la paidofilia y la homosexualidad. En 1865, Jules Amédée Barbey d'Aurevilly publicó la novela $U n$ prêtre marié en la que el personaje -un cura casado- a pesar de todas sus cualidades humanas, era más delincuente que el peor de los asesinos. En 1866 vio la luz en Valparaíso (Chile) la Historia del celibato forzoso y sus efectos, obra escrita en francés, publicada después en castellano en Londres y reproducida en Chile (Meyer, 2009, pp. 5, 9, 11) escrita por el pastor protestante estadounidense David Trumbull, quien llegó a Chile en diciembre de 1845 motivado por varios propósitos, entre ellos implementar un plan de expansión del protestantismo en América Latina. Para ello, Trumbull fue comisionado por dos organismos estadounidenses,

19. El Ideal Católico, (Puerto Rico), 23 de diciembre de 1899, p. 158

20. Ibid., 6 de enero de 1900, p. 174; La Democracia, (Puerto Rico), 9 de febrero de 1900, p. 3; La Correspondencia de Puerto Rico, 4 de enero de 1900, p. 2. El periódico madrileńo El Imparcial declaró que la noticia fue publicada por L'Osservatore Romano al tiempo que explicó que era apócrifa. El diario católico de Madrid El Siglo Futuro atribuyó su invención al periódico masónico La Tribuna de Valparaíso (Chile). Véase: El Imparcial, (Madrid), 31 de diciembre de 1899, p. 2.

21. Sobre el tema del celibato en las iglesias orientales véase: Cholij, 1990, pp. 113-127.

22. Podría aquí seguir dando ejemplos, pero no es el eje del artículo. 
la Foreign Evangelical Society y la Seaman's Friend Society. Cabe recalcar que este ministro protestante también era masón pues fue diputado de la Gran Logia de Massachusetts (Guerra Rojas, 2006, pp. 55-57).

No era esta la primera vez que circulaba un documento pseudo pontificio. El 13 de marzo de 1887 se fundó en Clinton (Iowa) la American Protective Association (APA), organización anticatólica que consideraba a los miembros de esta comunidad como un peligro para la seguridad nacional y pretendía, entre otras cosas, prohibir la ocupación de puestos gubernamentales a los católicos. ${ }^{23}$ Esta asociación comenzó en la clandestinidad e intentó resucitar los postulados de los Know Nothing, grupo que por su naturaleza fue denominado así. Según la APA, los católicos pretendían convertir su fe en religión única y exclusiva de la nación gracias a su monumental ascenso en la escala económica y a su penetración en las esferas sociales en las que los protestantes habían predominado hasta entonces. La asociación empezó a propagar sentimientos anticatólicos a lo largo de todo el país por medio de la literatura y la prensa y llegó a contar con más de setenta órganos de difusión semanal. Los sacerdotes que abandonaban el catolicismo eran acogidos siempre y cuando estuvieran prestos a combatir esa religión. La asociación también publicó una supuesta encíclica del papa León XIII en la que el pontífice recomendaba exterminar a los herejes en Estados Unidos de América, aniquilación fijada supuestamente para el 31 de julio de 1893 , fiesta de san Ignacio de Loyola. La APA se encargó de manipular a la población mediante una conspiración de prensa y predicaciones y conminó al pueblo a armarse, pues el exterminio católico romano se aproximaba y había que defenderse. Se afirmaba que en todas las parroquias los católicos estaban siendo entrenados en el uso de armas de fuego las cuales se emplearían en la fecha mencionada. Al llegar el día señalado y no suceder nada, la APA alegó haber impedido el suceso al amedrentar a los católicos (Pattee, 1946, pp.200-201, 204-208).

La circulación de la supuesta encíclica se dio en el contexto de una nación protestante y anticatólica que por sus raíces y su contexto histórico favorecía al protestantismo en contra del catolicismo, todo bajo un ambiente de naturalidad y aparente neutralidad. Era una especie de estado confesional en el que una falsa neutralidad religiosa fue utilizada para acrecentar la animadversión y los prejuicios contra el catolicismo romano y tallarlos con martillo y cincel en el imaginario colectivo estadounidense. El ambiente más propicio para ello fue la educación, en la cual se empleaban textos que incitaban un marcado odio hacia los católicos (Hernández Aponte, 1913, pp. 71-72, 94-96, 99, 369).

\section{Conclusión}

El catolicismo en Latinoamérica recibió un vigoroso impulso con el concilio (Cuenca Toribio, 1972, p. 562). La situación eclesial latinoamericana requirió la unión de fuerzas nacionales y continentales para consolidar acciones pastorales eficaces (Jaime Pérez, 2000, p. 875). La búsqueda de esta unidad católica se daba en unas circunstancias en las cuales diversos sectores anticatólicos unían fuerzas contra la Iglesia. Por ejemplo, en 1891 se trató de establecer una asociación que bajo el nombre de Grande Oriente Espiritista fusionaba el espiritismo y la masonería, con el objeto de fundar la Federación Masónica Espiritista Iberoamericana (Álvarez Lázaro, 1985, pp. 189-190, 345-348). Del 20 al 24 de octubre de 1892 se celebró en Madrid el Congreso Espiritista Iberoamericano e Internacional (Congreso, 1893) y en este contexto histórico varios rotativos latinoamericanos publicaron en 1899 una encíclica apócrifa del papa León XIII con el fin de conciliar el catolicismo con la modernidad. Ante el fracaso de este propósito los liberales se dieron a la tarea de secularizar la sociedad en oposición al catolicismo y en esa maquinación política colaboraron protestantes, masones y espiritistas. Cabe la posibilidad de que este documento fuera escrito con el fin de destruir la unidad latinoamericana católica que el papa León XIII quería había logrado con gran esfuerzo. Recordemos que la masonería obstaculizó la labor de la Iglesia católica romana en algunos países latinoamericanos (Henkel, 2000, p. 803; Pazos y Piccardo, 2002, p. 45) y llevó a cabo acciones subversivas contra la ella en Europa. Además, en 1884 el sumo pontífice respondió enérgicamente con la encíclica Humanum Genus en la que conde- 
naba los postulados masónicos como contrarios a la justicia y a la moral natural y ponía en evidencia las consecuencias que sobrevendrían en caso de que asociaciones con tales principios se hicieran al control de los estados (Leonard, 2000, pp. 877-878; Encíclicas, 1959, pp. 308-319). En este sentido el hecho podría verse como una posible venganza de dicha asociación contra el magno proyecto pontificio.

Considero necesario investigar a fondo qué repercusiones tuvo la publicación de la encíclica apócrifa de León XIII en 1899, cuán efectiva y rápida fue la acción de la santa sede al declararla nula, quién o quiénes emitieron el documento y por qué, cuántos sacerdotes se casaron o comenzaron a cortejar mujeres a raíz de su publicación, cómo actuaron los distintos prelados latinoamericanos a raíz del suceso, fue realmente una conspiración anticlerical originada por una logia masónica chilena y si hubo realmente una agenda anticlerical planificada detrás de la redacción y publicación del pseudo documento pontificio. Finalmente, creo pertinente contrastar hechos, acciones y escenarios a fin de tener una perspectiva global del asunto. Por otro lado, sería interesante investigar si además de las dos encíclicas apócrifas atribuidas a León XIII se publicaron otras y si ello es así creo menester un estudio grupal de ellas así como de sus motivos y consecuencias.

\section{Apéndice}

\section{Transcripción del documento pontificio apócrifo}

Nos León Papa XIII. Por la gracia de Dios su Vicario en la tierra.

A vosotros, venerables Arzobispos, Obispos, sacerdotes y fieles de la América Latina.

Nos dirigimos: Dandóos á conocer lo que Nos, después de consultar á los Venerables Padres del Concilio, decretamos:
$1^{\circ}$-Considerando que el celibato eclesiástico no es de derecho divino, sino dispuesto y ordenado por los sabios Concilios de los primeros siglos de la Iglesia y por nuestros predecesores en el Pontificado, atendiendo tanto á la mayor pureza en la celebración de los santos misterios, como por motivo de celos, trabajo y abnegación de parte de los sacerdotes en los dificiles deberes encomendados á su ministerio; disciplina que exigia la circunstancia de los tiempos, habiendo sobradas vocaciones para el servicio de la Iglesia.

$2^{\circ}$-Considerando que en la presente época y de un modo especialisimo en la América Latina, las vocaciones al Sacerdocio se hacen cada día más escasas, quedando muchas feligresias (sic) acéfalas por escasez del clero, con detrimento para la fé y servicio religioso.

$3^{\circ}$-Considerando que la causa más poderosa por la cual la juventud nacida y creada en la atmósfera materialista del presente siglo, se aparta del Sacerdocio es el Celibato Eclesiástico, que si bien es cierto, rodea de gran respeto y autoridad al sacerdote, también es verdad que exige una virtud y sacrificio heróico; para lo cual se necesita una gracia especialísima de Dios y que por lo mismo no á todos les es dada.

En virtud de estas poderosas resoluciones, y después de consultar á los Venerables Padres del Concilio Americano, Venimos en declarar: que dejamos en libertad á los sacerdotes seculares de dicha región, y sólo en razón de las necesidades apremiantes del clero en esas naciones y pueblos, para que puedan abrazar el estado del matrimonio, sujetándose en todo, con respecto á esta materia, á la disciplina general establecida por la Iglesia con respecto a los fieles.

Sin dejar poe (sic) esto de aconsejaros, en estas mismas letras como más perfecto santo y digno del sacerdote el conservaros célibes.

Esta facultad principiará á regir desde el $1^{\circ}$ de Enero de 1900.

Dado en Roma, a diez (sic) de Julio (sic) del año del Señor, 1899 y vigésimo de nuestro Pontificado.

León Papa XIII ${ }^{24}$. 


\section{Bibliografía}

- Actas y decretos del Concilio Plenario de la América Latina. Roma: Librería Editrice Vaticana, 1999.

- AGUER, Héctor Rubén (2000). "Los documentos del Concilio Plenario de América Latina. Análisis teológico, jurídico y pastoral". En Los últimos cien años de la evangelización en América Latina. Centenario del Concilio Plenario de América Latina. Os últimos cem anos da evangelização na América Latina: centenário do Concílio Plenário da América Latina. Simposio histórico: Ciudad del Vaticano, 21-25 de junio de 1999. Actas. Roma: Librería Editrice Vaticana, pp. 235-254.

- ALEJOS GRAU, Carmen José (2005). "Fuentes para el estudio de los concilios latinoamericanos del siglo XX". En Anuario de Historia de la Iglesia XIV. pp. 301-311.

- ALEJOS GRAU, Carmen José (2000). "La recepción del Concilio Plenario de América Latina en el Código de Derecho Canónico de 1917”. En Los últimos cien años de la evangelización en América Latina. Centenario del Concilio Plenario de América Latina. Os últimos cem anos da evangelização na América Latina: centenário do Concilio Plenário da América Latina. Simposio histórico: Ciudad del Vaticano, 21-25 de junio de 1999. Actas. Roma: Librería Editrice Vaticana. pp. 419-427.

- ÁlVAREZ LÁZARO, Pedro F. (1985). Masonería y librepensamiento en la España de la Restauración. Madrid, España: Publicaciones de la Universidad Pontificia de Comillas.

- ARDAO, Arturo (1950). Espiritualismo y positivismo en el Uruguay. Filosofias universitarias de la segunda mitad del siglo XIX. México, D. F.: Fondo de Cultura Económica.

- BASTIAN, Jean-Pierre (1994). Protestantismos y modernidad latinoamericana. Historia de unas minorías religiosas activas en América Latina. México, D. F.: Fondo de Cultura Económica.

- BAUTISTA GARCÍA, Cecilia Adriana (2005). "Hacia la romanización de la iglesia mexicana a fines del siglo XIX”. En Historia Mexicana, julio-septiembre, ańo LV, núm. 1, pp. 99-144.

- BOLETÍN ECLESIÁSTICO DE LA DIÓCESIS DE PUERTO RICO (1898).

- CHOLIJ, Roman (1990). "El celibato sacerdotal en la Iglesia Oriental". En Lucas F. Mateo Seco, La formación de los sacerdotes en las circunstancias actuales. Pamplona: Servicios de Publicaciones, Universidad de Navarra. pp. 113-127

- CONGRESO Espiritista Ibéricoamericano é Internacional celebrado en Madrid... desde el 20 al 24 de Octubre de 1892. Madrid: Dionisio de los Ríos, 1893.

- CUENCA TORIBIO, José Manuel (1972). "Notas para el estudio de la Iglesia Suramericana durante los pontificados de León XIII y Pío XII”. En Anuario de Estudios Americanos, XXIX. pp. 557-573.

- EL IDEAL CATÓLICO, [Puerto Rico], (1899-1900).

- EL IMPARCIAL, [Madrid], (1899).

- ENCÍCLICAS PONTIFICIAS (1959). Colección completa 1832-1959. Tomo I. Buenos Aires: Editorial Guadalupe.

- FAZIO, Mariano (2000). "Iglesia y liberalismo en Hispanoamérica durante el siglo XIX. El caso Sarmiento". En Los últimos cien años de la evangelización en América Latina. Centenario del Concilio Plenario de América Latina. Os últimos cem anos da evangelização na América Latina: centenário do Concílio Plenário da América Latina. Simposio histórico: Ciudad del Vaticano, 21-25 de junio de 1999. Actas. Roma: Librería Editrice Vaticana. pp. 643-657.

- GONZÁLEZ, Fidel (2000). “Aplicación, frutos y proyección del Concilio Plenario Latinoamericano”. En Los últimos cien años de la evangelización en América Latina. Centenario del Concilio Plenario de América Latina. Os últimos cem anos da evangelização na América Latina: centenário do Concílio Plenário da América Latina. Simposio histórico: Ciudad del Vaticano, 21-25 de junio de 1999. Actas. Roma: Librería Editrice Vaticana. pp. 255-317. 
- GUERRA ROJAS, Cristián (2006). "La música en los inicios de los cultos cristianos no católicos en Chile: el caso de la Union Church (Iglesia Unión) de Valparaíso, 1845-1890”. En Revista Musical Chilena, año LX, julio-diciembre (206). pp. 49-83.

- HENKEL, Willi (2000). Leone XIII e l'America Latina. En Los últimos cien años de la evangelización en América Latina. Centenario del Concilio Plenario de América Latina. Os últimos cem anos da evangelização na América Latina: centenário do Concilio Plenário da América Latina. Simposio histórico: Ciudad del Vaticano, 21-25 de junio de 1999. Actas. Roma: Librería Editrice Vaticana. pp. 803-811.

- HERNÁNDEZ APONTE, Gerardo Alberto (2013). La Iglesia Católica en Puerto Rico ante la invasión de Estados Unidos de América. Lucha, sobrevivencia y estabilización: (1898-1921). San Juan de Puerto Rico: Editorial Tiempo Nuevo y el Auspicio de la Academia Puertorriqueńa de la Historia y el Decanato de Estudios Graduados e Investigación (DEGI) de la Universidad de Puerto Rico, Recinto de Río Piedras (en prensa).

- JAIME PÉREZ, Francisco Javier (2000). "Conciencia y misión de iglesia en el Concilio Plenario de América Latina”. En Los últimos cien años de la evangelización en América Latina. Centenario del Concilio Plenario de América Latina. Os últimos cem anos da evangelização na América Latina: centenário do Concílio Plenário da América Latina. Simposio histórico: Ciudad del Vaticano, 21-25 de junio de 1999. Actas. Roma: Librería Editrice Vaticana. pp. 861-876.

- KINZER, Donald L. (1964). An Episode in Anti-Catholicism: The American Protective Association. Seattle: University of Washington Press.

- LA CORRESPONDENCIA DE PUERTO RICO (1899-1900).

- LA DEMOCRACIA, [Puerto Rico], (1899-1900).

- LASKI, Harold J. (1939). El liberalismo europeo: un ensayo en interpretación, México, D.F.: Fondo de Cultura Económica.

- LEONARD, Donald (2000). "La masonería en América Latina. El caso de México”. En Los últimos cien años de la evangelización en América Latina. Centenario del Concilio Plenario de América Latina. Os últimos cem anos da evangelização na América Latina: centenário do Concílio Plenário da América Latina. Simposio histórico: Ciudad del Vaticano, 21-25 de junio de 1999. Actas. Roma: Librería Editrice Vaticana. pp. 877-893.

- LÓPEZ, Teodoro (1997). "León XIII y la cuestión social (1891-1903)”. En Josep-Ignasi Saranyana (ed.), Cien años de pontificado romano: de León XIII a Juan Pablo II. Pamplona, España: Ediciones Universidad de Navarra. pp. 19-37. Los últimos cien años de la evangelización en América Latina. Centenario del Concilio Plenario de América Latina. Os últimos cem anos da evangelização na América Latina: centenário do Concilio Plenário da América Latina. Simposio histórico: Ciudad del Vaticano, 21-25 de junio de 1999. Actas. Roma: Librería Editrice Vaticana, 2000.

- LYNCH, John (1991). "La Iglesia Católica en América Latina, 1830-1930”. En Leslie Bethell (editora), Historia de América Latina. Barcelona: Editorial Crítica 8. pp. 65-122.

- MALLIMACI, Fortunato (2004). "Catolicismo y liberalismo: las etapas del enfrentamiento por la definición de la modernidad religiosa en América Latina”. En Jean-Pierre Bastian, (coord.), La modernidad religiosa. Europa latina y América Latina en perspectiva comparada. México D. F.: Fondo de Cultura Económica. pp. 19-44.

- MARTÍNEZ DE ARTOLA, Víctor (2003). "Magisterio pontificio y Asambleas eclesiásticas en América Latina en el siglo XX”. En Anuario de Historia de la Iglesia XII. pp.406-411.

- MEYER, Jean (2009). El celibato sacerdotal católico en los siglos XIX y XX. México: Centro de Investigación y Docencia Económicas.

- MORALES PADRÓN, Francisco (2000). "Relaciones diplomáticas entre la Santa Sede y las Repúblicas latinoamericanas en tiempos del Concilio Plenario". En Los últimos cien años de la evangelización en América Latina. Centenario del Concilio Plenario de América Latina. Os últimos cem anos da evangelização na América

$146 \varangle$ Universidad de San Buenaventura, Cali - Colombia 
Latina: centenário do Concilio Plenário da América Latina. Simposio histórico: Ciudad del Vaticano, 21-25 de junio de 1999. Actas. Roma: Librería Editrice Vaticana. pp. 1021-1035.

- NEGRÓN-PORTILLO, Mariano (1981). El autonomismo puertorriqueño su transformación ideológica (18951914): la prensa en el análisis social, la democracia de Puerto Rico. Río Piedras: Ediciones Huracán.

- PATTEE, Ricardo (1946). El catolicismo en los Estados Unidos. Madrid: EPESA Ediciones y Publicaciones Españolas, S.A.

- PAZOS, Antón M. y PICCARDO, Diego R. (2002). El Concilio Plenario de América Latina. Roma 1899. Madrid: Iberoamericana.

- PAZOS, Antón M. (1998). "El iter del Concilio Plenario Latino Americano de 1899 o la articulación de la Iglesia latinoamericana”. En Anuario de Historia de la Iglesia VII. pp. 185-206.

- PAZOS, Antón M. (2000). "Preparación y convocatoria del Concilio Plenario de la América Latina". En Los últimos cien años de la evangelización en América Latina. Centenario del Concilio Plenario de América Latina. Os últimos cem anos da evangelização na América Latina: centenário do Concílio Plenário da América Latina. Simposio histórico: Ciudad del Vaticano, 21-25 de junio de 1999. Actas. Roma: Librería Editrice Vaticana. pp. 149-184.

- PEDREIRA, Antonio S. (1982). El periodismo en Puerto Rico. Río Piedras: Editorial Edil, Inc.

- RODRÍGUEZ ESTRADA, Mauro (1969). El celibato eclesiástico ante la biblia, la psicología y la historia. México: Editorial Trillas.

- SANZ, Mariano (2000). "La metodología del Conciliar Plenario de America Latina". En Los últimos cien años de la evangelización en América Latina. Centenario del Concilio Plenario de América Latina. Os últimos cem anos da evangelização na América Latina: centenário do Concílio Plenário da América Latina. Simposio histórico: Ciudad del Vaticano, 21-25 de junio de 1999. Actas. Roma: Librería Editrice Vaticana. pp. 1267-1284.

- SARANYANA, Josep-Ignasi (2005). Cien años de Teología en América Latina (1899-2001). Bogotá, D. C.: Consejo Episcopal Latinoamericano (CELAM).

- VÉLIZ, Claudio (1984). La tradición centralista de América Latina. Barcelona: Editorial Ariel.

- VICARIO, Francisco, S.C.M. (1909). “Apuntes para la historia de la Congregación de la Misión en la isla de Puerto Rico". En Anales de la Congregación de la Misión fundada por San Vicente de Paúl. Madrid: Imprenta del Asilo de Huérfanos del S. C. de Jesús, tomo XVII. pp. 583-626. 